\title{
EVALUATION OF PETROLEUM HYDROCARBONS ELUTION FROM SOIL
}

\author{
Janina Piekutin ${ }^{1}$ \\ 1 Bialystok University of Technology, 45A Wiejska Str., 15-351 Bialystok, Poland, e-mail: j.piekutin@pb.edu.pl
}

Received: 2015.05.13

Accepted: 2015.06.02

Published: 2015.07.01

\begin{abstract}
The paper presents studies on oil removal from soil by means of water elution with a help of shaking out the contaminants from the soil. The tests were performed on simulated soil samples contaminated with a mixture of petroleum hydrocarbons. The study consisted in recording the time influence and the number of elution cycles to remove contaminants from the soil. The samples were then subject to the determination of petroleum hydrocarbons, aliphatic hydrocarbons, and BTEX compounds (benzene, toluene, ethylbenzene, xylene). Due to adding various concentrations of petroleum into particular soil samples and applying different shaking times, it was possible to find out the impact of petroleum content and sample shaking duration on the course and possibility of petroleum substances removal by means of elution process.
\end{abstract}

Keywords: soil, BTEX, petroleum hydrocarbons, elution, water.

\section{INTRODUCTION}

Currently, there are no accurate data on the amount of petroleum pollution penetrating the environment, as the recording and balancing covers only the huge spills, while thousands of small leaks that do not have witnesses and not affecting the local ecosystem damage, are literally hidden [Kajdas 1979; Taubman and Blum 1967]. It is assumed that an average of $0.1-0.25 \%$ of used oil enters the soil and aqueous environment in the form of leakage. The division of leakage may be represented due to [Taubman and Blum 1967]:

- the reason of origin (natural leakage or resulting from human activity),

- type of released substance (leakage of raw petroleum or processed and enriched oil products),

- amount of released material,

- elements of polluted environment,

- leakage duration (impulse or persisted leakage).

Even a single spill of large quantity of petroleum products on the soil surface usually results in a formation of a hydrocarbons pool that gradually disappears due to the contaminants penetration into the groundwater medium. Time interval between the appearance of this substance on the surface and its complete absorption can be considered a contaminant pulse duration (Fąfara and Miska 2005; Fąfara and Rychlicki 2005). The main purpose of the mechanism of oil elution from the porous structures is undoubtedly the increase of mobilization of the oil backlog formation (Fąfara and Rychlicki 2005).

The paper presents a study on the removal of petroleum products from the soil by means of elution with water and shaking out the contaminated soil.

\section{MATERIALS AND METHODS}

Laboratory tests were conducted to investigate the possibilities and the course of petroleum substances removal from soil by means of crude oil elution from the soil structure using water. The elution studies were carried out using the soil samples laboratory contaminated with the petroleum hydrocarbons mixture. The area localized far from the traffic and anthropogenic pollution was selected for study due to the need of possibly the lowest contents of petroleum and its derivatives in the ground. The soil was collected and subject to determinations within two 
months (in March and April). That time, 15 soil samples were analyzed applying following processing stages:

- sample preparation by means of increasing the petroleum contents added to particular samples,

- triple elution of petroleum from the soil for every sample by means of shaking technique,

- observations of the influence of soil sample shaking duration on the elution efficiency.

Due to adding various concentrations of petroleum into particular soil samples and applying different shaking times, it was possible to find out the impact of petroleum content and sample shaking duration on the course and possibility of petroleum substances removal by means of elution process. Amounts of added petroleum and duration of sample shaking are presented in Table 1.

The test samples consisted of soil with addition of petroleum and distilled water and were prepared directly before tests. The initial weight of every sample was $150 \mathrm{~g}$ of soil. Then, increasing quantities of petroleum as well as $180 \mathrm{ml}$ of distilled water were added into every soil sample. In order to carry out the petroleum elution process, each sample was shaken for specified time in a shaker. Water, along with eluted petro- leum-derivative contaminants after shaking, was decanted into the beaker, then $180 \mathrm{ml}$ of distilled water was added into each and shaken again for 10 minutes. The process was three times repeated for every analyzed soil sample.

After elution of the petroleum substances, soil samples were subject to chromatographic determination. Each sample was acidified using nitric acid $\left(0.5 \mathrm{~cm}^{3}\right)$, then magnesium sulfate $(10 \mathrm{~g})$ and $\mathrm{n}$ hexane $(50 \mathrm{ml})$ were added. Samples were then stirred on electromagnetic stirrer for 30 minutes. After that, the fractions were separated in laboratory separator. Water fraction was removed, while organic fraction was subject to further analyses due to the petroleum substances contained. Each sample was transferred into the containers and sealed after adding sodium sulfate and florisil.

Such prepared samples were subject to chromatographic determination to find the concentrations of petroleum substances Analysis was performed applying gas chromatography technique using gas chromatograph coupled with spectrophotometer by VARIAN of type 4000 . The device was equipped in capillary column $\mathrm{VF}-5 \mathrm{MS}$ filled with stationary phase made of polydimethyloiloxane containing $5 \%$ of phenyl moieties. The length of the column was $20 \mathrm{~m}$, inner diameter $0.25 \mathrm{~mm}$, film thickness $0.25 \mu \mathrm{m}$.

Table 1. Mineral oil and n-alkanes concentrations in samples for subsequent elutions of petroleum from the soil using water

\begin{tabular}{|c|c|c|c|c|}
\hline Series & Elution sequence & Shaking duration & $\begin{array}{c}\text { Mineral oil concentration } \\
{\left[\mathrm{mg} \cdot \mathrm{dm}^{-3}\right]}\end{array}$ & $\begin{array}{c}\text { n-alkanes sum concentration } \\
{\left[\mathrm{mg}^{\prime} \mathrm{dm}^{-3}\right]}\end{array}$ \\
\hline \multirow{3}{*}{1} & 1 & 10 & 58.26 & 0.0282 \\
\hline & 2 & 10 & 79.06 & 0.0295 \\
\hline & 3 & 10 & 0.39 & 0.0310 \\
\hline \multirow{3}{*}{2} & 1 & 10 & 108.64 & 0.0294 \\
\hline & 2 & 10 & 0.52 & 0.0303 \\
\hline & 3 & 10 & 0.77 & 0.0340 \\
\hline \multirow{3}{*}{3} & 1 & 10 & 427.70 & 0.1192 \\
\hline & 2 & 10 & 8.08 & 0.0363 \\
\hline & 3 & 10 & 0.83 & 0.0313 \\
\hline \multirow{3}{*}{4} & 1 & 10 & 1.16 & 0.0203 \\
\hline & 2 & 10 & 0.53 & 0.0210 \\
\hline & 3 & 10 & 0.44 & 0.0251 \\
\hline \multirow{3}{*}{5} & 1 & 10 & 34.19 & 0.0298 \\
\hline & 2 & 10 & 0.45 & 0.0303 \\
\hline & 3 & 10 & - & - \\
\hline \multirow{3}{*}{6} & 1 & 10 & 1.21 & 0.0283 \\
\hline & 2 & 10 & 7.46 & 0.0298 \\
\hline & 3 & 10 & 0.86 & 0.0361 \\
\hline
\end{tabular}




\section{RESULTS AND DISCUSSION}

Presented concentrations of mineral oil are high in the case of two first elutions, after which these level considerably decrease (Table 1). The highest concentration achieved after the second elution was $79.06 \mathrm{mg} \cdot \mathrm{dm}^{-3}$, while the lowest one was observed after the last elution $\left(0.39 \mathrm{mg} \cdot \mathrm{dm}^{-3}\right)$. Content of n-alkanes sum gradually increased along with the number of elutions. Minimum after the first elution was $0.0282 \mathrm{mg} \cdot \mathrm{dm}^{-3}$, whereas maximum recorded after the third elution was $0.031 \mathrm{mg} \cdot \mathrm{dm}^{-3}$.

The second series was characterized by very high removal of mineral oil just after the first soil elution. The value was $108.64 \mathrm{mg} \cdot \mathrm{dm}^{-3}$, which makes much higher level as compared to the content of this substance after subsequent elutions, during which mineral oil concentration oscillated from $0.5 \mathrm{mg} \cdot \mathrm{dm}^{-3}$ to $0.8 \mathrm{mg} \cdot \mathrm{dm}^{-3}$. Concentration of n-alkanes in subsequent samples gradually increased. Their minimum level reached after the first soil elution amounted to $0.0294 \mathrm{mg} \cdot \mathrm{dm}^{-3}$, while maximum $\left(0.034 \mathrm{mg} \cdot \mathrm{dm}^{-3}\right)$ was recorded after the third elution cycle.

Results of the third series revealed that both mineral oil and n-alkanes sum concentrations decreased along with subsequent elution. The maximum value reached after the first soil elution was $427.7 \mathrm{mg} \cdot \mathrm{dm}^{-3}$ for mineral oil and $0.1192 \mathrm{mg} \cdot \mathrm{dm}^{-3}$ for n-alkanes sum. The lowest concentrations were recorded for the last elution amounting to $0.83 \mathrm{mg} \cdot \mathrm{dm}^{-3}$ for mineral oil and $0.0313 \mathrm{mg} \cdot \mathrm{dm}^{-3}$ for sum of $n$-alkanes. It was also noted that the highest levels of mineral oil and n-alkanes sum were much higher as compared to the results achieved after subsequent elutions.

Contents of mineral oil in the third tested series gradually decreased. The highest value was $1.16 \mathrm{mg} \cdot \mathrm{dm}^{-3}$, while the lowest $0.44 \mathrm{mg} \cdot \mathrm{dm}^{-3}$. Concentration after the first elution of mineral oil was over $50 \%$ higher than for subsequent elutions. In contrast, sum of n-alkanes gradually increased. Minimum reached after the first elution amounted to $0.0203 \mathrm{mg} \cdot \mathrm{dm}^{-3}$, and maximum after the last elution increased up to $0.0251 \mathrm{mg} \cdot \mathrm{dm}^{-3}$.

Analysis of soil elution in the fourth series revealed that in the case of mineral oil, its content after the first elution was much higher than after subsequent one. Concentrations of n-alkanes sum reached higher levels after the second than after the first soil elution. Mineral oil concentration decreased from $34.19 \mathrm{mg} \cdot \mathrm{dm}^{-3}$ to $0.045 \mathrm{mg} \cdot \mathrm{dm}^{-3}$, whereas that of n-alkanes sum increased from $0.0298 \mathrm{mg} \cdot \mathrm{dm}^{-3}$ to $0.0303 \mathrm{mg} \cdot \mathrm{dm}^{-3}$. Only two results for elution of sample No 14 are presented due to the fact that beaker was broken during the third petroleum elution by means of shaking.

In the fifth series, the mineral oil concentration in the last testes sample reached its maximum level $\left(7.46 \mathrm{mg}^{\circ} \mathrm{dm}^{-3}\right)$ after the second, while minimum $\left(0.86 \mathrm{mg} \cdot \mathrm{dm}^{-3}\right)$ after the last elution. Considering the sum of $\mathrm{n}$-alkanes content in test soil samples, their gradual increase from 0.0283 $\mathrm{mg} \cdot \mathrm{dm}^{-3}$ to $0.0361 \mathrm{mg} \cdot \mathrm{dm}^{-3}$ was recorded after subsequent elution cycles.

The highest concentration values were achieved in the first series after the second elution, whereas the lowest - after the last elution process. In the case of the latter, the maximum value $\left(21.09 \mathrm{mg} \cdot \mathrm{dm}^{-3}\right)$ was recorded for $\mathrm{m}+\mathrm{p}$ xylene, while minimum $\left(6.3 \mathrm{mg} \cdot \mathrm{dm}^{-3}\right)$ for ethylbenzene. The lowest concentrations were found after the last elution and among these values, the lowest $\left(0,44 \mathrm{mg} \cdot \mathrm{dm}^{-3}\right)$ was determined for ethylbenzene and the highest $\left(1.5 \mathrm{mg} \cdot \mathrm{dm}^{-3}\right)$ for $\mathrm{m}+\mathrm{p}$ xylene.

A gradual decrease in the concentrations during the second series is noteworthy. Definitely the highest values were achieved after the first elution. Among these results, the highest was represented by $\mathrm{m}+\mathrm{p}$ xylene amounting to 18.21 $\mathrm{mg} \cdot \mathrm{dm}^{-3}$ and the lowest by ethylbenzene equal to $5.82 \mathrm{mg} \cdot \mathrm{dm}^{-3}$. Minimum levels of analyzed aromatic hydrocarbons were recorded after the last elution of petroleum from tested soil samples by means of shaking. Among all BTEX concentrations, the lowest content was reached by ethylbenzene, i.e. $0.66 \mathrm{mg} \cdot \mathrm{dm}^{-3}$.

The highest values of concentrations of analyzed aromatic hydrocarbons presented in the third series were achieved after the first elution. Amount of eluted BTEX's was much higher than their contents in samples after subsequent elutions (Table 2). The highest numbers were recorded for $\mathrm{m}+\mathrm{p}$ xylene $\left(80.4 \mathrm{mg} \cdot \mathrm{dm}^{-3}\right)$, while the lowest for ethylbenzene $\left(0.53 \mathrm{mg} \cdot \mathrm{dm}^{-3}\right)$. These samples differed from other ones with prolonged shaking duration (15 minutes instead of 10 minutes).

The obtained results for aromatic hydrocarbons elution in the fourth series are relatively similar. The lowest values were achieved after the second, while the highest after the first elution. The largest content $\left(2.47 \mathrm{mg} \cdot \mathrm{dm}^{-3}\right)$ after the first elution was recorded for $\mathrm{m}+\mathrm{p}$ xylene, whereas the smallest $\left(0.87 \mathrm{mg} \cdot \mathrm{dm}^{-3}\right)$ for ethylbenzene. In the 
Table 2. Content of BTEX's in samples after subsequent elutions

\begin{tabular}{|c|c|c|c|c|c|}
\hline Sample & Elution sequence & $\begin{array}{c}\text { Toluene } \\
{\left[\mathrm{mg} \cdot \mathrm{dm}^{-3}\right]}\end{array}$ & $\begin{array}{c}\text { Etylbenzene } \\
{\left[\mathrm{mg}^{-} \mathrm{dm}^{-3}\right]}\end{array}$ & $\begin{array}{c}\mathrm{m}+\mathrm{p} \text { ksylene } \\
{\left[\mathrm{mg}^{2} \cdot \mathrm{dm}^{-3}\right]}\end{array}$ & $\begin{array}{l}\text { o-ksylene } \\
{\left[\mathrm{mg}^{\left.-\mathrm{dm}^{-3}\right]}\right.}\end{array}$ \\
\hline \multirow{3}{*}{1} & 1 & 10.71 & 4.83 & 15.25 & 6.80 \\
\hline & 2 & 19.24 & 6.30 & 21.09 & 9.15 \\
\hline & 3 & 1.60 & 0.44 & 1.50 & 0.67 \\
\hline \multirow{3}{*}{2} & 1 & 10.40 & 5.82 & 18.21 & 8.27 \\
\hline & 2 & 5.83 & 1.87 & 6.28 & 2.82 \\
\hline & 3 & 2.33 & 0.66 & 2.28 & 1.05 \\
\hline \multirow{3}{*}{3} & 1 & 59.77 & 21.00 & 80.40 & 35.78 \\
\hline & 2 & 11.37 & 3.15 & 11.41 & 5.06 \\
\hline & 3 & 2.15 & 0.53 & 1.85 & 0.83 \\
\hline \multirow{3}{*}{4} & 1 & 2.22 & 0.87 & 2.47 & 1.07 \\
\hline & 2 & 0.99 & 0.36 & 1.07 & 0.47 \\
\hline & 3 & 1.88 & 0.41 & 1.42 & 0.65 \\
\hline \multirow{3}{*}{5} & 1 & 19.76 & 5.11 & 19.14 & 8.11 \\
\hline & 2 & 1.29 & 0.36 & 1.12 & 0.47 \\
\hline & 3 & - & - & - & - \\
\hline \multirow{3}{*}{6} & 1 & 5.46 & 1.76 & 6.08 & 2.62 \\
\hline & 2 & 8.41 & 2.07 & 7.51 & 3.34 \\
\hline & 3 & 2.68 & 0.62 & 2.29 & 1.06 \\
\hline
\end{tabular}

case of the lowest BTEX concentrations recorded after the second elution, the minimum value $(0.36$ $\mathrm{mg} \cdot \mathrm{dm}^{-3}$ ) was achieved for ethylbenzene, while maximum $\left(1.07 \mathrm{mg} \cdot \mathrm{dm}^{-3}\right)$ for $\mathrm{m}+\mathrm{p}$ xylene.

Because a beaker was broken during the third elution of petroleum from the soil in the fifth series, results for only two samples after two subsequent elutions, are presented. Much higher levels were recorded after the first elution; these values oscillated from $5.11 \mathrm{mg} \cdot \mathrm{dm}^{-3}$ for toluene up to $19.76 \mathrm{mg} \cdot \mathrm{dm}^{-3}$ for ethylbenzene. The lowest value after the second elution $\left(0.36 \mathrm{mg} \cdot \mathrm{dm}^{-3}\right)$ was observed for ethylbenzene, whereas the highest $\left(1.29 \mathrm{mg} \cdot \mathrm{dm}^{-3}\right)$ for toluene.

The maximum concentrations during the sixth series of analyzed aromatic hydrocarbons were recorded after the second elution. The highest value $\left(8.41 \mathrm{mg} \cdot \mathrm{dm}^{-3}\right)$ within this group characterized toluene, while the lowest $\left(2.07 \mathrm{mg} \cdot \mathrm{dm}^{-3}\right)$ ethylbenzene. The lowest levels for BTEX's were observed after the last elution with the largest concentration $\left(2.68 \mathrm{mg} \cdot \mathrm{dm}^{-3}\right)$ for toluene and the smallest $\left(0.62 \mathrm{mg} \cdot \mathrm{dm}^{-3}\right)$ for ethylbenzene.

It follows both from the present study and research by Sęk [Sęk et al. 2011] that the elution of petroleum from the soil is an efficient method leading to remove the petroleum derivative contaminants out of the soil.

The tests revealed that he largest quantities of mineral oil were removed from the soil during the first elution cycle. This dependence made up almost $46.67 \%$ of the achieved results. However, very close value referring to the amount of eluted contaminants (40\%) was recorded during the second elution. The least petroleum derivatives were removed during the third elution - only $13.33 \%$; this stage contributed to the removal of the largest part of petroleum as compared to previous elutions. These results are confirmed by findings of Sęk [Sęk at al. 2011, Izdebska-Mucha 2005]. The author reported that high-viscous liquids are mainly eluted during the first stage. On a base of Sęk's studies, it can be also concluded that quantities of eluted oil are lower after subsequent elution cycles. However, such dependence was not confirmed by presented results, because in majority of test samples, content of mineral oil did not gradually decrease during subsequent elutions, instead this pattern was non-uniform.

It was also noted that in prevailing the majority of the analyzed samples (66.67\%), content of the mineral oil after the third elution was the lowest, which can prove that petroleum substances were eluted just in previous soil elution cycles. These results also find their reflection in publication by Sęk [Sęk et al 2011], who observed the lowest levels of eluted oil during the last elutions.

Studies carried out by Sęk [Sęk et al 2011]; Schobert [Schobert 1990] revealed that quite large amounts of petroleum substances can be 
relatively easily removed from the sand layer. This remark finds the confirmation also in the present study, because contents of eluted petroleum substances were remarkable in each of tested samples, which indicated the efficiency of applied method for these contaminants removal. In Sęk's opinion [Sęk et al 2011], taking into account the environmental protection, this fact means that the petroleum pollution transported along with the penetrating water, are able to reach very deep soil layers, and thus they can reach even the deep waters.

According to book by Barański and Gworek, [Barański and Gworek 2004] elution processes transfer hydrocarbons into the water phase due to their dissolution in water and transport in a form of solutions. Aromatic hydrocarbons, in particular BTEX's (benzene, toluene, xylene) are characterized by the best solubility. This feature can be a reason for the dependence noticed in the present study, i.e. the largest amounts of eluted substances can be reached just after subjecting the contaminated soil sample to the first elution cycle. Due to a good water-solubility of these hydrocarbons, their maximum elution is achieved during the first elution process.

The soil samples No 1-2 contained the same contents of petroleum as samples No 3-4. The difference between particular samples resulted from their shaking duration. In the case of samples No 10-12, the time was 10 minutes, while samples No 5-6 were shaken for 15 minutes (Table 2). It was noted at samples No 1-5 that despite the same petroleum contents in particular samples, the shaking duration significantly affected the decrease in petroleum substances eluted from the soil. Every sample with the same content of petroleum and longer shaking time in subsequent elution cycles, contained much less petroleum substances. Soils are porous formations and the pores become clogged at the moment of petroleum penetration, which in consequence leads to aggregation of soil particles and increase in its compactness. Taking into considerations the prolonged time for their shaking, the added petroleum could considerably better penetrate its pores and clog the sand particles, which later resulted in more difficult elution of petroleum substances.

In the case of n-alkanes it was noted that the process of their elution was relatively nonuniform. It was found that the highest quantity of eluted substances was contained not in samples after the first, but subsequent elutions. For n-alkanes, their largest concentration after the first elution was achieved only in three analyzed samples, which makes $20 \%$ of obtained results. Observed differences in the n-alkanes elution process course can result from their unique feature, i.e. resistance towards both physical and chemical influences.

\section{CONCLUSIONS}

The present study allowed for verifying the course and possibilities to remove petroleum from the soil. Due to the fact that a specified quantity of petroleum was added into every sample, there was a certainty that each of them was contaminated with petroleum substances.

Achieved results of mineral oil contents in samples after subsequent elution revealed that these substances can be readily eluted from soils and the process appeared to be the most efficient just during the first elution cycle, when concentration of petroleum substances was usually the highest.

It was noted in the case of n-alkanes that their elution process was not uniform and there was not any univocal dependence among obtained results. However, method for elution of petroleum substances for these hydrocarbons is also efficient, although maximum and minimum yields are reached at different elution stages for different samples.

BTEX are best eluted from analyzed soils. Their largest amounts are removed after the first elution, which can indicate their vulnerability towards water elution from analyzed samples.

Considering the shaking duration, it was observed that increasing the time had no significant impact on the efficiency of performed elution process; and on the contrary, mineral oil content after elution was lower in the case of samples that were shaken for the longer time. Therefore, elution was less efficient than for samples containing the same petroleum concentration and shorter shaking duration [Seifert and Teeter 1970; Glass 2000; Jewulski and Zagrajczuk 2005; Bear and Yavuz Corapcioglu 1987; Pastewski et al. 2009].

It was stated that elution process makes removal of remarkable quantities of analyzed chemicals present in petroleum, hence the petroleum itself, from the soil [Rychlicki, Fąfara 2006; Lewkiewicz-Małysa at al. 2008; Paudyn 2008]. This method does not require any sophisticated 
device and allows for relatively fast treatment of contaminated soil. Unfortunately, it is quite invasive for natural environment due to the necessity to transport the soil from its location (exsitu method) [Harmsen et al. 2008; Barnes, Asce 2003, Wolejko at al. 2014]. Both investment and operational costs for application of petroleum substances removal from the soil are quite high, which is associated with the need to build a proper installation, and mainly with a transport the treated soil to the device.

On the basis of the results achieved from studies upon possibility and course of petroleum elution from the soil structures it was stated that the elution process can be applied to remove petroleum contamination from soil and gives satisfactory results, and the elution time of petroleumcontaminated soil samples does not affect the efficiency of the process. The shorter shaking time, the better elution efficiency.

\section{Acknowledgements}

The study was carried out at Department of Technology in Engineering and Environmental Protection, Bialystok University of Technology from funds for statute activity.

\section{REFERENCES}

1. Barański A., Gworek B. 2004. Evaluation of health and environmental risk due to grounds contaminated with petroleum substances. Monograph 11-13, 55-64 (in Polish).

2. Barnes D.L., Asce M. 2003. Estimation of operation time for soil vapor extraction systems. Journal of Environmental Engineering 129, 873.

3. Bear J., Yavuz Corapcioglu M. 1987. Advances in transport phenomena in porous media. Martinus Nijhoff Publishers, Boston, 269-343.

4. Fąfara Z., Miska W. 2005. Dispersion of petroleum contamination in a ground in a view of laboratory studies. Wiertnictwo Nafta Gaz 22, 127-132 (in Polish).

5. Fąfara Z., Rychlicki S. 2005.) Influence of the ground properties on hydrocarbons migration on a base of laboratory studies. Wiertnictwo Nafta Gaz 22, 135-136 (in Polish).
6. Glass D.S. 2000. The petrochemical interface in: modern petroleum technology. Institute of Petroleum, 149-158.

7. Harmsen J., Rulkens W.H., Sims R.C., Rijtema P.E., Zweers A.J. 2008. Theory and application of landfarming to remediate polycyclic aromatic hydrocarbons and mineral oil-contaminated sediments: Beneficial Reuse. J. Environ Qual 36, 1112-1122.

8. Izdebska-Mucha D. 2005. Influence of oil pollution on selected geological-engineering properties of clay soils. Przegląd Geologiczny, 53, 766-769 (in Polish).

9. Jewulski J., Zagrajczuk D. 2005. Selection of parameters for contamination removal from the ground by means of chemical method on a base of laboratory studies. Wiertnictwo Nafta Gaz, 22, 157-158 (in Polish).

10. Kajdas Cz. Chemistry and physicochemistry of petroleum. (Chemia i fizykochemia ropy naftowej), 1979, 16 - 371 (in Polish).

11. Lewkiewicz-Małysa A., Rogowska-Kwas R., Wind B. 2008. Reduction in the contents of hydrocarbon polluting the natural environment, Wiertnictwo Nafta Gaz 25, 454-455 (in Polish).

12. Rychlicki S., Fąfara Z. et al. (Eds) 2006. Methods for removal of hydrocarbon contaminants from the ground-water environment (in Polish).

13. Pastewski S., Czacharowski P., Mędrzycka K. 2009. Washing out of hydrophobic organic pollutants from Soil using surfactants solutions. Monograph Polska Inżynieria Środowiska 1(58), 183 (in Polish).

14. Paudyn K., Paudyn K., Rutter A., Rowe R.K., Poland J.S., 2008. Remediation of hydrocarbon contaminated soils in the Canadian Arctic by landfarming. Cold Regions Sience and Technology 53, 102-114.

15. Schobert H.H. 1990. The chemistry of hydrocarbon fuels. Butterworths, London.

16. Seifert W.K., Teeter R.M. 1970. Identification of polycyclic aromatic and heterocyclic crude oil carboxylic acids. Anal. Chem., 42, 750.

17. Sęk J. Dziubiński M., Błaszczyk M., Padyk A. 2011. Studies upon penetration of plant oils and petroleum substances solutions through porous medium. Inżynieria Ekologiczna 26, 48-49.

18. Taubman J., Blum A. 1967. Petroleum in a contemporary world, 10-67 (in Polish).

19. Wołejko E., Butarewicz A., Wydro U., Łoboda T. 2014. Advantages and potential risks of municipal sewage sludge application to urban soil. Desalination and Water Treatment, 52, 3732-3742. 